\title{
Cigarette Smoking and Root Filled Teeth Extraction: Systematic Review and Meta-Analysis
}

\author{
Daniel Cabanillas-Balsera ${ }^{1} \mathbb{D}$, Juan J. Segura-Egea ${ }^{1, *} \mathbb{C}$, María C. Jiménez-Sánchez ${ }^{2}$, \\ Victoria Areal-Quecuty ${ }^{1}$ (D), Benito Sánchez-Domínguez ${ }^{1}$, Paloma Montero-Miralles ${ }^{1}$ (D), \\ Juan J. Saúco-Márquez ${ }^{1}$ and Jenifer Martín-González ${ }^{1, *}$ \\ 1 Department of Stomatology, Section of Endodontics, School of Dentistry, University of Sevilla, 41009 Sevilla, \\ Spain; danielcaba@gmail.com (D.C.-B.); v.arealquecuty@hotmail.com (V.A.-Q.); beni2506@yahoo.es (B.S.-D.); \\ montero_paloma@hotmail.com (P.M.-M.); jjsauco@us.es (J.J.S.-M.) \\ 2 Materials Science Institute of Sevilla (ICMS), Joint CSIC-University of Sevilla Center, 41092 Sevilla, Spain; \\ jimenezsanchez6@gmail.com \\ * Correspondence: segurajj@us.es (J.J.S.-E.); jmartin30@us.es (J.M.-G.)
}

Received: 1 September 2020; Accepted: 29 September 2020; Published: 30 September 2020

\begin{abstract}
AbstractAim: The aim of this systematic review and meta-analysis was to investigate the possible association between smoking habits and the occurrence of root-filled teeth (RFT) extraction. Material and Methods: The Population, Intervention, Comparison, and Outcome (PICO) question was in adult patients who had RFT, does the absence or presence of smoking habits affect the prevalence of extracted RFT? Systematic MEDLINE/PubMed, Wiley Online Database, Web of Science, and PRISMA protocol was used to evaluate and present the results. The Grading of Recommendations, Assessment, Development, and Evaluation (GRADE) system was used for certainty in the evidence. The risk of bias was assessed according to Cochrane Collaboration common scheme for bias and ROBINS-I tool. Cumulative meta-analysis was performed with a random effects model. PROSPERO registration code: CRD42020165279. Results: After search strategy, 571 articles were recovered, seven were selected for full-text analysis, and two reported data on inclusion criteria, including 516 RFT, 351 in non-smokers, and 165 in smoker subjects. The meta-analysis provided an odds ratio indicating significant association between smoking and the prevalence of extracted RFT (OR $=3.43,95 \% \mathrm{CI}$ $\left.=1.17-10.05, p=0.02, \mathrm{I}^{2}=64 \%\right)$. The certainty of the literature assessment was low per GRADE. Both studies were considered as moderate risk of bias. Conclusions: Tobacco smoking should be considered a negative prognostic factor for the outcome of root canal treatment, although the quality of the evidence is low. RFT of smoking patients are three times more likely to be extracted. Continuing to smoke after endodontic treatment may increase the risk of treatment failure. However, the overall strength of evidence is low. This must be considered a limitation of the present study and the conclusion should be valued with caution.
\end{abstract}

Keywords: endodontic medicine; endodontics; root canal treatment outcome; smoking habits; root-filled teeth extraction; tobacco smoking

\section{Introduction}

Periapical inflammatory reaction caused and maintained by bacterial antigens from the root canal is named apical periodontitis [1]. Apical periodontitis (AP) is a very prevalent disease, ranging $0.6-20 \%$ of teeth $[2,3]$. The diagnosis of AP is made by analyzing the patient's symptoms and signs, and can be confirmed radiographically by the disruption of the lamina dura and the presence of a radiolucent area encircling root apex, namely radiolucent periapical lesion (RPL) [4]. To cure AP, it is necessary to interrupt the passage of antigens from inside the root canal to the periapical tissue. 
This is achieved through root canal treatment (RCT) [5]. RCT can fail for different reasons [6], such as inadequate endodontic technique (including deficient aseptic control, missed canals, inadequate instrumentation, etc.) $[7,8]$, root resorption, root fractures, or high bone lost [9-11], persisting periapical inflammation [12]. When it is not possible to perform non-surgical retreatment or apical surgery, RFT should be removed $[13,14]$.

As mentioned above, the causes involved in extraction of RFT are many, being difficult to assess the role that each of them plays. One of the factors that has been studied in recent years is the systemic state of the patient $[15,16]$. Some systemic diseases can induce a pro-inflammatory status, altering immune response and impairing periapical healing $[15,17]$. This is the case of diabetes, which has recently been identified as a risk factor for non-retention of RFT [18].

Smoking coincides with diabetes in causing a systemic pro-inflammatory state and impaired immune response, having been associated with oral pathologies such as severe periodontal disease, pre-malignant lesions of the oral mucosa, oral cancer, caries, and high rate of treatment failure $[19,20]$. The dental pulp and periapical tissues of smokers show diminished defensive and reparative responses [21], as well as impaired bone healing [22]. Therefore, it is expected that the prevalence of $\mathrm{AP}$ is higher in smokers and, subsequently, that they also have a higher prevalence of RFT. A recently published systematic review with meta-analysis has concluded that smokers are 2.5 times more likely to have AP, being RCT almost three times more prevalent in smokers, compared to non-smoker subjects [23]. Moreover, a dose-response relationship between tobacco smoking and RCT have been found [24]. However, the possible effect of smoking on the outcome of endodontic treatment and its influence on RFT loss is uncertain, reaching several epidemiological studies contradictory conclusions $[15,25,26]$. The aim of this systematic review and meta-analysis was to investigate the possible association between smoking habits and the prevalence of extracted RFT.

\section{Materials and Methods}

The protocol of this systematic review has been developed and registered in the PROSPERO database (PROSPERO 2020 CRD42020165279). The systematic review has been developed according to the Preferred Reporting Items for Systematic Reviews and Meta-Analyses (PRISMA) Guidelines [27].

\subsection{Review Question}

The present review focused on the following research question: Does the presence or absence of smoking habits affect the prevalence of extracted RFT in adult patients? PICO (Population, Intervention, Comparison, and Outcome) schema for all the included studies to elaborate upon this research question were used to establish the eligibility criteria as follows:

Population: Adults patients with root-filled teeth.

Intervention: Presence of smoking habits, smoker.

Comparison: Absence of smoking habits, non-smoker.

Outcome: Extraction of root-filled teeth.

\subsection{Inclusion and Exclusion Criteria}

The inclusion criteria established were (a) epidemiological studies published between January 1980 to June 2020; (b) studies comparing smoking patients with non-smoking subjects; (c) studies including RFT; (d) studies providing data on the prevalence of extracted RFT, both in smoker subjects and in control non-smoking patients. Exclusion criteria were defined as (a) studies carried out in animals or in cell culture, and (b) studies reporting data only from smoking subjects. When there was no initial agreement among the reviewers, consensus was reached through dialogue. 


\subsection{Literature Search}

Once the PICO question was established, the search strategy was designed [28,29]. Studies located in the search were selected according to inclusion and exclusion criteria, quality evaluation, and data extraction, and analysis. A literature search in MEDLINE/PubMed, Scopus, Web of Science, and Wiley Online Database was achieved using the following Mesh terms and keywords (Box 1): (Tobacco OR Smoking OR Smoker) AND (endodontic OR endodontics OR endodontic treatment OR root canal preparation OR root canal therapy OR root filled teeth OR endodontically treated teeth) AND (extraction OR retention OR dental avulsion OR avulsion OR tooth loss OR survival OR success OR failure OR outcome).

Box 1. MeSH and key words combinations used for the search strategy for the Population, Intervention, Comparison, and Outcome (PICO) question: In adult patients who had root filled teeth, does the absence or presence of smoking habits affect the prevalence of extracted root filled teeth?

((“tobacco"[MeSH Terms] OR “tobacco"[All Fields] OR “tobacco products"[MeSH Terms] OR ("tobacco"[All Fields] AND "products"[All Fields]) OR "tobacco products"[All Fields]) OR ("smoking"[MeSH Terms] OR "smoking"[All Fields]) OR ("smokers"[MeSH Terms] OR "smokers"[All Fields] OR "smoker"[All Fields])) AND (endodontic[All Fields] OR ("endodontics"[MeSH Terms] OR “endodontics"[All Fields]) OR (endodontic[All Fields] AND ("therapy"[Subheading] OR “therapy"[All Fields] OR "treatment"[All Fields] OR “therapeutics"[MeSH Terms] OR "therapeutics"[All Fields])) OR ("root canal preparation"[MeSH Terms] OR ("root"[All Fields] AND "canal"[All Fields] AND "preparation"[All Fields]) OR "root canal preparation"[All Fields]) OR ("root canal therapy"[MeSH Terms] OR ("root"[All Fields] AND "canal"[All Fields] AND "therapy"[All Fields]) OR "root canal therapy"[All Fields]) OR (("plant roots"[MeSH Terms] OR ("plant"[All Fields] AND "roots"[All Fields]) OR "plant roots"[All Fields] OR "root"[All Fields]) AND filled[All Fields] AND ("tooth"[MeSH Terms] OR “tooth"[All Fields] OR “teeth"[All Fields])) OR ("tooth, nonvital”[MeSH Terms] OR ("tooth"[All Fields] AND "nonvital"[All Fields]) OR "nonvital tooth"[All Fields] OR ("endodontically"[All Fields] AND “treated"[All Fields] AND "teeth"[All Fields]) OR “endodontically treated teeth"[All Fields])) AND (extraction[All Fields] OR ("retention, psychology"[MeSH Terms] OR ("retention"[All Fields] AND "psychology"[All Fields]) OR "psychology retention"[All Fields] OR "retention"[All Fields]) OR (("dental health services"[MeSH Terms] OR ("dental"[All Fields] AND “health"[All Fields] AND "services"[All Fields]) OR "dental health services"[All Fields] OR "dental"[All Fields]) AND ("fractures, avulsion"[MeSH Terms] OR ("fractures"[All Fields] AND "avulsion"[All Fields]) OR "avulsion fractures"[All Fields] OR "avulsion"[All Fields])) OR ("fractures, avulsion"[MeSH Terms] OR ("fractures"[All Fields] AND "avulsion"[All Fields]) OR "avulsion fractures"[All Fields] OR "avulsion"[All Fields]) OR ("tooth loss"[MeSH Terms] OR ("tooth"[All Fields] AND "loss"[All Fields]) OR "tooth loss"[All Fields]) OR ("mortality"[Subheading] OR "mortality"[All Fields] OR “survival”[All Fields] OR “survival”[MeSH Terms]) OR success[All Fields] OR failure[All Fields] OR outcome[All Fields])

A hand-search was also carried out in main endodontic journals (International Endodontic Journal, Journal of Endodontic, and Australian Endodontic Journal) and in the references of significant papers and reviews. The last search was made in June of 2020.

Electronic and manual searches provided the titles and abstracts of articles related to the aims of the studies, which were categorized by three independent researchers (D.C.-B., J.M.-G., and J.J.S.-E.) according to the inclusion and exclusion criteria. Articles selected were full-text reviewed by four investigators (D.C.-B., J.M.-G., P.M.-M., and J.J.S.-E.).

\subsection{Data Extraction}

The methodology of selected studies was examined, and main features were extracted and compiled including, authors, date of publication, study design, subjects and sample size, main quantitative results and odds ratio values, and diagnosis of RPLs. Data extraction was performed by four investigators (D.C-B., J.M-G., M.C.J-S., and J.J.S-E). Disagreements were resolved by discussing between the four and reaching an agreement by majority. When necessary to clarify the data, the authors of the included studies were consulted. 


\subsection{Outcome Variables and Statistical Analysis}

The primary outcome was the prevalence of extracted RFT. Odds ratio (OR), with its $95 \%$ confidence interval (CI) was calculated in every selected study trying to measure the effect of the relationship between smoking habits and the outcome of RCT. A random-effect model meta-analysis, on the basis of inverse variance method, was performed to determine the pooled OR and its $95 \% \mathrm{CI}$.

To estimate the variance and heterogeneity amongst trials, the Tau ${ }^{2}$ and the Higgins $\mathrm{I}^{2}$ tests were employed, taking into account that substantial heterogeneity is considered if $\mathrm{I}^{2}$ test is higher than $50 \%$ [30]. A funnel plot was plotted to illustrate the possible existence of publication bias [31]. To show the OR results, a forest plot [32] was used, along with the inverse variance pooled estimate. Finally, a level of $p=0.05$ was considered significant. The meta-analyses were calculated with the 5.4 RevMan software (Review Manager Web. The Cochrane Collaboration, 2019. Available at revman.cochrane.org) [33].

\subsection{Quality Evidence Assessment and Risk of Bias in Individual Studies}

The quality of evidence of the included studies was analysed according to the guidelines provided by the Centre for Evidence-Based Medicine at Oxford [34]. The certainty in the evidence was assessed using the GRADE tool (GRADEpro GDT: GRADEpro Guideline Development Tool [Software]. Available from gradepro.org: https://gdt.gradepro.org/app/handbook/handbook.html\#h.rkkjpmwb6m6z [35]. The GRADE tool has five domains: risk of bias, inconsistency, imprecision, indirectness, and publication bias, that can be downgraded and reduce the quality of the evidence [36]. Articles were assessed independently by 4 reviewers (J.J.S.E., J.M.G., D.C.B., and M.C.J.S.) and cases of disagreements in the risk of bias were discussed until a consensus was achieved.

The risk of bias of the included studies was assessed according to Cochrane Collaboration common scheme for bias and ROBINS-I tool [37], initially described to assess nonrandomized studies of interventions, but currently also available for observational designs (https://methods.cochrane.org/ robins-i-tool).

\section{Results}

The search strategy is presented in Figure 1. After searching databases and hand-searching relevant bibliographies/papers, 571 articles were recovered. Excluding duplicates articles $(n=384)$ and publications before $1980(n=1), 186$ articles were checked to satisfy the selection criteria by titles and abstract, declaring seven articles for full text review. Applying inclusion and exclusion criteria and assessing the level of evidence and the quality of all full articles read, only two were included in the meta-analysis. Five articles were excluded because of two reasons (Table 1): absence of data about how many RFT existed at the beginning of the study [38-41], and absence of data about how many RFT were extracted [17].

Table 1. Studies excluded in the systematic review of association between smoking habits and the prevalence of root-filled teeth extraction. Excluded reason, authors, and year of these studies.

\begin{tabular}{ccc}
\hline Excluded Reason & Authors & Year \\
\hline \multirow{2}{*}{$\begin{array}{c}\text { Not provide necessary data to } \\
\text { meta-analysis (absence initial } \mathrm{n}^{\circ} \text { RFT) }\end{array}$} & 1. Zadik et al. & 2008 [38] \\
\cline { 2 - 3 } & 2. Zhong et al. & $2010[39]$ \\
\cline { 2 - 3 } & 3. Touré et al. & $2011[40]$ \\
\cline { 2 - 3 } & 4. Olcay et al. & 2018 [41] \\
\hline $\begin{array}{c}\text { Not provide necessary data to } \\
\text { meta-analysis (absence } \mathrm{n}^{\circ} \text { RFT extracted) }\end{array}$ & 5. Marending et al. & 2005 [17] \\
\hline
\end{tabular}




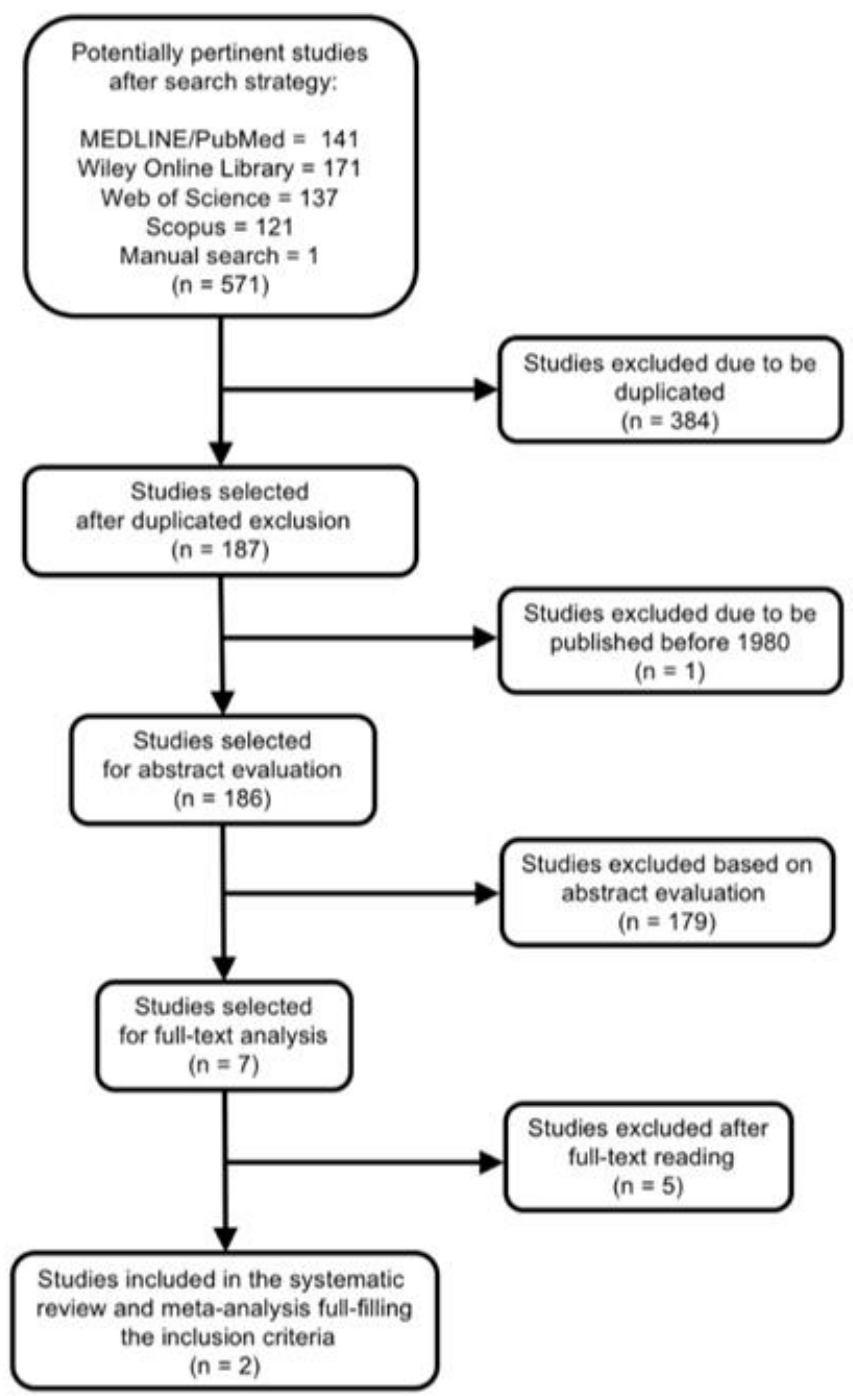

Figure 1. Flow diagram showing the process by which the studies about tobacco smoking and the prevalence of root filled teeth extraction were selected.

\subsection{Study Characteristics}

Finally, two studies were included in the analysis: 1. Doyle et al. [20], and 2. Khalighinejad et al. [42]. Study design, smokers and controls subjects, main data, and evidence level [34] are summarized in Table 2.

Table 2. Studies about smoking habits and the prevalence of root filled teeth extraction included in the systematic review. Study design, subjects and sample size, main results, and evidence level [34].

\begin{tabular}{cccccc}
\hline Authors & Year & Study Design & RCT & $\begin{array}{c}\text { Association } \\
\text { Diab.-Extr.RFT }\end{array}$ & $\begin{array}{c}\text { Evidence } \\
\text { Level [34] }\end{array}$ \\
\hline 1. Doyle et al. & $2007[20]$ & $\begin{array}{c}\text { Retrospective } \\
\text { chart review } \\
\text { (follow up } 1 \\
\text { years) } \\
\text { Longitudinal } \\
\text { 2. Khalinghinejad } \\
\text { et al. }\end{array}$ & $\begin{array}{c}\text { Controls: } 158 \\
\text { Smokers: } 38\end{array}$ & YES; $p=0.0004$ & $3 \mathrm{~b}$ \\
2017 [42] & $\begin{array}{c}\text { Controls: } 193 \\
\text { years) }\end{array}$ & Smokers: 127 & YES; $p=0.003$ & $3 \mathrm{~b}$ \\
\hline
\end{tabular}

RCT: root canal treatment; RFT: root-filled teeth; Extracted*RFT: extracted root-filled teeth. 


\subsection{Meta-Analysis}

A table of evidence was elaborated with data of both selected articles (Table 3). The estimated variance among the two studies was examined by Tau ${ }^{2}$ test, resulting non-significant $\left(\mathrm{Tau}^{2}=0.41\right.$; $\mathrm{Chi}^{2}=2.81 ; \mathrm{df}=1 ; p=0.09$ ).

Table 3. Studies about smoking habits and the prevalence of root filled teeth extraction. Results extracted and compiled, descriptive statistics and odds ratios calculated.

\begin{tabular}{|c|c|c|c|c|c|c|c|c|}
\hline \multirow[b]{2}{*}{ Authors } & \multirow[b]{2}{*}{ Year } & \multirow{2}{*}{$\begin{array}{l}\text { Number } \\
\text { of RFT }\end{array}$} & \multicolumn{2}{|c|}{ Non-Smoker Controls } & \multicolumn{2}{|c|}{ Smoker Patients } & \multirow{2}{*}{$\begin{array}{c}\text { OR } \\
\text { (95\% C.I.) }\end{array}$} & \multirow[b]{2}{*}{$p$} \\
\hline & & & $\begin{array}{l}\text { Extracted }{ }^{*} \text { RFT/ } \\
\text { Total RFT }\end{array}$ & $\begin{array}{c}\text { Extracted }{ }^{*} \text { RFT } \\
(\%)\end{array}$ & $\begin{array}{l}\text { Extracted }^{*} \text { RFT/ } \\
\text { Total RFT }\end{array}$ & $\begin{array}{c}\text { Extracted }{ }^{*} \text { RFT } \\
(\%)\end{array}$ & & \\
\hline Doyle et al. & $\begin{array}{l}2007 \\
{[20]}\end{array}$ & 196 & $5 / 158$ & $3.2 \%$ & $7 / 38$ & $18.4 \%$ & $\begin{array}{c}6.9 \\
(2.1-23.2)\end{array}$ & 0.0004 \\
\hline $\begin{array}{l}\text { Khalinghinejad } \\
\text { et al. }\end{array}$ & $\begin{array}{l}2017 \\
{[42]}\end{array}$ & 320 & $32 / 193$ & $16.6 \%$ & $39 / 127$ & $30.7 \%$ & $\begin{array}{c}2.2 \\
(1.31-3.81) \\
\end{array}$ & 0.003 \\
\hline OVERALL & & 516 & $37 / 351$ & $10.5 \%$ & $46 / 165$ & $27.9 \%$ & $\begin{array}{c}3.43 \\
(1.2-10.1)\end{array}$ & 0.002 \\
\hline
\end{tabular}

RFT: root-filled teeth. Extracted*RFT: extracted root filled teeth. ${ }^{*}$ Inverse variance method: Chi $^{2}=2.80 ; p=0.002$.

Heterogeneity test value $\left(\mathrm{I}^{2}=64 \%\right)$ was high; therefore, both weights were calculated using the random effects model, considering there was variation among the included studies and allowing the study outcomes to vary in a normal distribution (Figure 2, Funnel plot).

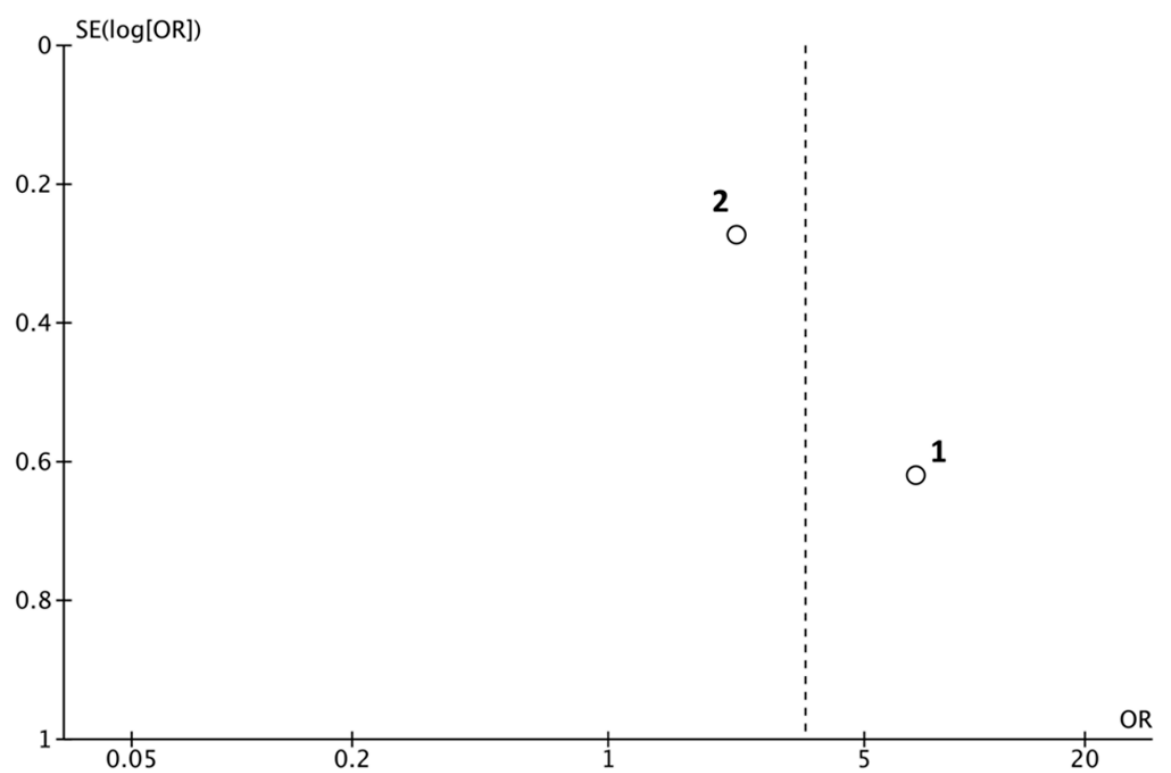

Figure 2. Funnel plot for estimates in meta-analysis of extracted root-filled teeth (RFT) in smoker subjects. Studies with higher power and lower standard error are placed towards the top. Studies with lower power are placed towards the bottom. 1. Doyle et al. (Scott L. Doyle et al., [20]) and 2. Khalighinejad et al. (Khalighinejad et al., [42]).

Overall OR was calculated using inverse variance method with random effects, resulting an $\mathrm{OR}=$ $3.43(95 \% \mathrm{CI}=1.17-10.05 ; p=0.02)$. The ORs for each study and the pooled OR from the meta-analysis were shows in a forest plot (Figure 3). This result indicates that there is a significant difference in the prevalence of extracted RFT between smoking patients and control subjects. 


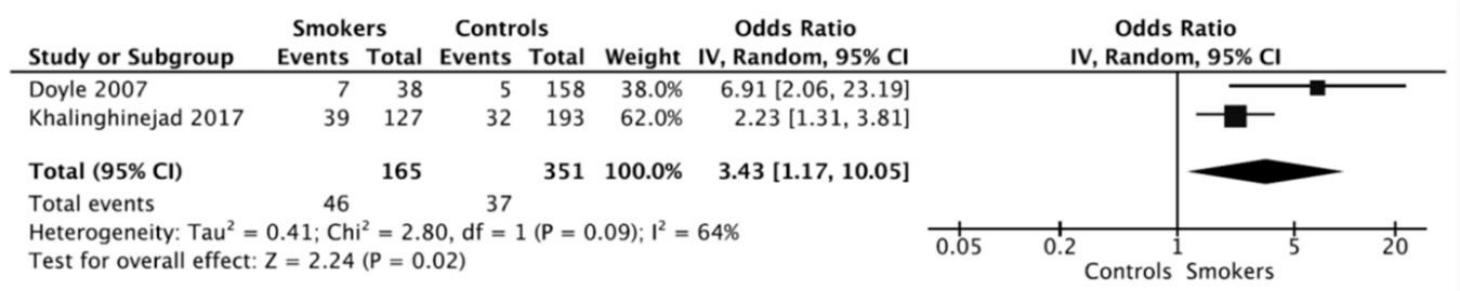

Figure 3. Forest plot of ORs and 95\% confidence limits (CL) for the comparison of smokers and healthy control subjects regarding the frequency of extracted root-filled teeth (RFT). Overall estimate is based on data from the two studies. Black squares represent the point estimate of the odds ratio and have areas proportional to study size. Lines represent $95 \%$ confidence intervals. The diamond shows the summary statistic for the two studies. The solid line indicates an odds ratio of 1.0, and the dashed line indicates the overall odds ratio. OR: odds ratio; LCL: lower confidence level; UCL: upper confidence level.

\subsection{Interpretation and Assessment of the Included Studies}

The two studies included in the meta-analysis are retrospective, being published in 2007 [43] and 2017 [42]. With the results of the two studies, data from 516 RFT, 351 non-smokers, and 165 smokers were collected. In the study of Doyle et al. [43], the information from 367 patient's charts was collected for a period of time of 10 years and clinical data, number of RFT, periapical index of RFT, patient's habits, and type of restorations were determined. A positive association between smoking habits and the extraction of RFT was found. Smokers showed significantly higher percentage of extracted RFT $(18.4 \%)$ compared with non-smokers $(3.2 \%)(\mathrm{OR}=6.91 ; 95 \% \mathrm{CI}=2.06-23.19 ; p=0.00043)$.

The second study, Khalighinejad et al. [42], classified RFT according to their periodontal status and in addition also collected personal data. Nine years after, the authors evaluated teeth that required extraction and the factors that were related to this. The outcome revealed an increased risk of RFT extraction between smokers $(30.7 \%)$, compared with non-smokers $(16.6 \%)(\mathrm{OR}=2.23 ; 95 \% \mathrm{CI}=$ $1.31-3.81 ; p=0.0029)$.

\subsection{Quality Evidence Assessment}

The scores [34] for the two studies were low, as both studies were scored with $3 b$ (Table 2). The GRADE tool also demonstrated a low quality of the evidence for the included studies indicating that the true effect might be markedly different from the estimated effect (Table 4). Both included studies received the "serious" classification for the risk of bias, attending the limitations in the studies design and execution (see Figure 4-summary bias individual). Additionally, as detailed previously, the studies might have had substantial inconsistency, with an $\mathrm{I}^{2}$ statistic $=64 \%$ and $\mathrm{Tau}^{2}=0.41$, so the "serious" for the inconsistency factor was received. The "not serious" classification was assigned for the indirectness and imprecision domains, and as other considerations, a strong association was evidenced, and a plausible residual confusion would reduce proved effect.

Table 4. GRADE Working Group grades of evidence: Smoking habits and the prevalence of root filled teeth extraction.

\begin{tabular}{|c|c|c|c|c|c|c|c|c|}
\hline \multicolumn{7}{|c|}{ Certainty Assessment } & \multirow{2}{*}{ Certainty } & \multirow{2}{*}{ Importance } \\
\hline $\begin{array}{l}\text { Number } \\
\text { of Studies }\end{array}$ & Study Design & $\begin{array}{c}\text { Risk of } \\
\text { Bias }\end{array}$ & Inconsistency & Indirectness & Imprecision & $\begin{array}{c}\text { Other } \\
\text { Considerations }\end{array}$ & & \\
\hline \multicolumn{9}{|c|}{ Extracted root filled teeth } \\
\hline 2 & $\begin{array}{l}\text { Observational } \\
\text { studies }\end{array}$ & serious $^{a}$ & serious $^{b}$ & not serious & not serious & $\begin{array}{l}\text { strong association all } \\
\text { plausible residual } \\
\text { confounding would } \\
\text { reduce the } \\
\text { demonstrated effect }\end{array}$ & $\begin{array}{l}\oplus \oplus \circ \bigcirc \\
\text { Low }\end{array}$ & IMPORTANT \\
\hline
\end{tabular}

Explanations: a. Detailed in Figure 4: Risk of bias summary, b. $\mathrm{I}^{2}=64 \%$ and Tau $^{2}=0.41$, High certainty: The authors have a lot of confidence that the true effect is similar to the estimated effect, Moderate certainty: The authors believe that the true effect is probably close to the estimated effect, Low certainty: The true effect might be markedly different from the estimated effect, Very low certainty: The true effect is probably markedly different from the estimated effect. 


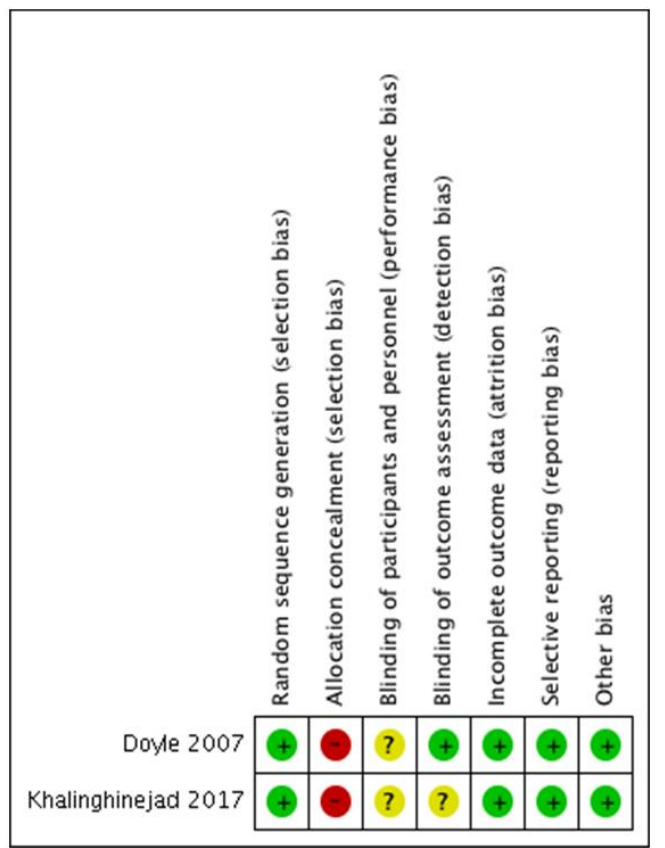

Figure 4. Risk of bias summary of included studies according the Cochrane Collaboration's tool for assessing risk of bias. + Low risk of bias. - High risk of bias. ? Unclear risk of bias.

According to ROBINS-I tool, both studies were considered as moderate risk of bias: Doyle et al. [20] with one domain classified as high and other as unclear, and Khalighinejad et al [42] with two unclear with other high risk of bias (Figure 4).

\section{Discussion}

This study aimed to analyze the possible link between smoking habits and the prevalence of extracted RFT. The results of the systematic review and meta-analysis carried out, including the available evidence about the prevalence of non-retained RFT, conclude that smoking is associated to RFT extraction.

After the literature search two studies providing follow-up data about RFT extraction were included: Doyle et al. [43] and Khalinghinejad et al. [42]. Both longitudinal studies analyzed the outcome of RCT in smokers and non-smoker patients, evaluating if the RFT was extracted or planned for extraction $[42,43]$.

The random effects model was used to calculate overall ORs allowing the study outcomes to vary in a normal distribution. Furthermore, the heterogeneity value was moderate (64\%), showing the relatively great variability between the studies. The inverse variance method reported an overall $\mathrm{OR}=3.43(p=0.02)$, indicating that smokers are 3.4 times more likely to lose RFT, compared to non-smoker subjects. Both included studies are longitudinal, allowing a temporal link to be established between cigarette smoking and losing endodontically treated teeth.

The implications that the results of this meta-analysis have in the daily dental clinic are very important. Moreover, translational medicine involves bringing the results of epidemiological studies into clinical practice. Dentists must know that tobacco smoking is a negative prognostic factor for the outcome of endodontic treatment. Smoking patients should also know that their prognosis for RCT has lower expectations of success. If, in addition to smoking, patients have other risk factors such as cardiovascular disease $[44,45]$ or diabetes $[18,46,47]$, smokers should know that their RFTs have very high likelihood to end up being lost.

The association between smoking and the prevalence of extracted RFT had not been investigated so far by meta-analysis. Thus, the result of the present study fill this knowledge gap. However, 
the quality level of the two included studies is low (3b), because of this, the results of the present systematic review and meta-analysis should be valued with caution. The GRADE tool demonstrated an overall low strength of evidence. This implies that true effect might be markedly different from the estimated effect. Although the sample size is high in both studies, there are important drawbacks in their design that lowers up to "serious" their classification for the risk of bias. This must be considered a limitation of this study.

The present systematic review has other limitations. One is the possible bias of the results by the reason of the tooth extractions. The loss of RFT is interpreted as RCT failure, but it could be due to other simultaneous cofactors, such as periodontal disease, trauma, or increasing the age of patients [48-50]. Only one of the studies took into consideration the periodontal status of RFT [42]. Smoking periodontal patients probably display higher prevalence of extractions, since smoking is associated to severe periodontitis [51]. Teeth with moderate or severe periodontitis could have even three times more risk to lost, especially if these teeth do not receive an adequate periodontal treatment or if the patient are a smoker [42,52]. On the other hand, the two included studies did not take into account the dose-response effect. Then, it is impossible to determine if the alleged relationship meets the dose-effect criterion for be considered causal. Therefore, prospective studies are needed that take into account the dose-effect factor evaluating the amount of tobacco smoked and the time during which you have smoked. Another limitation of the present study is that grey literature has not been analyzed.

The results of this systematic review indicate that tobacco influences the post-endodontic periapical healing process, increasing three times the probability that treatment will fail and that the tooth will need to be extracted. The effect of cigarette smoking on periapical tissues repair after endodontic treatment has biological plausibility [15]. Several biological mechanisms can be argued. Tobacco smoking can affect the healing process of the RFT hindering bone repair and maintaining destructive periapical bone processes $[15,53,54]$. In this way, periapical lesion in the smoker's RFT could have a slower healing process, establishing persistent apical periodontitis, which would lead to tooth loss [15,55]. Cigarette smoking alters leukocytes, macrophages, and T-cell lymphocytes functions, decreasing antibodies levels [56], and increasing the levels of pro-inflammatory mediators (IL-6, TNF$\alpha$, C-reactive protein) [54,57-59]. Alterations in microcirculation, both morphological and functional, could also have an impact on periapical healing after endodontic treatment and cause the loss of the RFT. It is possible that the inflamed periapical tissues of smokers have an insufficient supply of nutrients and oxygen [15]. Cigarette smoking would increase the level of carboxyhemoglobin as well as oxidative stress, altering micro-vascularization and decreasing the supply of oxygen and nutrients to the repair periapical tissues [60]. Furthermore, smoking is associated to delay fibroblast migration to the wound area and fibroblast dysfunction [61]. It has been shown that cigarette smoking has local and direct pro-inflammatory effect on inflamed periapical tissues, with increased levels of products of lipid peroxidation, such as 8-iso-PGF (2a), and products of the LOX-pathway [62]. Lastly, cigarette smoking, stimulating osteoclastic cells and reducing angiogenesis, impairs bone healing and tissues reparative response [63,64].

\section{Conclusions}

The results of the available studies indicate a significant relationship between smoking and higher prevalence of non-retained RFT. Tobacco smoking should be considered a negative prognostic factor for the outcome of root canal treatment. Dentists should know that RFT are much more likely to be extracted in smokers, explaining to patients that maintaining smoking after undergoing endodontic treatment can increase the risk of treatment failure. However, the meta-analysis includes only two studies, both of low quality level and serious risk of bias. Therefore, the overall strength of evidence is low, and this must be considered a limitation of the present study. Because of this, the conclusion should be valued with caution. Better designed longitudinal studies are needed to accurately define the impact of smoking on the outcome of endodontic treatment. 
Author Contributions: All authors have reviewed and approved the submitted version. The authors declare: Conceptualization, J.M.-G., D.C.-B., and J.J.S.-E.; methodology and software, D.C.-B., P.M.-M., and J.J.S.-E.; validation, J.J.S.-E., J.M.-G., D.C.-B., and M.C.J.-S.; formal analysis, M.C.J.-S. and D.C.-B.; investigation, V.A.-Q., J.J.S.-M., B.S.-D., and J.J.S.-E.; data curation, J.J.S.-E., J.M.-G., and D.C.-B.; writing-original draft preparation, J.J.S.-S. and D.C.-B.; writing-review and editing, D.C.-B., J.M.-G., J.J.S.-E., and P.M.-M.; visualization, V.A.-Q., J.J.S.-M., B.S.-D., and J.J.S.-E.; supervision, J.J.S.-E. and J.M.-G. All authors have read and agreed to the published version of the manuscript.

Funding: This research received no external funding.

Conflicts of Interest: The authors declare that they have no conflict of interest.

\section{References}

1. Ricucci, D.; Siqueira, J.F. Biofilms and apical periodontitis: Study of prevalence and association with clinical and histopathologic findings. J. Endod. 2010, 36, 1277-1288. [CrossRef] [PubMed]

2. Ahmed, I.; Ali, R.W.; Mudawi, A.M. Prevalence of apical periodontitis and frequency of root-filled teeth in an adult Sudanese population. Clin. Exp. Dent. Res. 2017, 3, 142-147. [CrossRef] [PubMed]

3. Kabak, Y.; Abbott, P.V. Prevalence of apical periodontitis and the quality of endodontic treatment in an adult Belarusian population. Int. Endod. J. 2005, 38, 238-245. [CrossRef] [PubMed]

4. Karabucak, B.; Bunes, A.; Chehoud, C.; Kohli, M.R.; Setzer, F. Prevalence of Apical Periodontitis in Endodontically Treated Premolars and Molars with Untreated Canal: A Cone-beam Computed Tomography Study. J. Endod. 2016, 42, 538-541. [CrossRef]

5. Ricucci, D.; Lin, L.M.; Spångberg, L.S.W. Wound healing of apical tissues after root canal therapy: A long-term clinical, radiographic, and histopathologic observation study. Oral Surg. Oral Med. Oral Pathol. Oral Radiol. Endodontol. 2009, 108, 609-621. [CrossRef]

6. Siqueira, J.F. Aetiology of root canal treatment failure: Why well-treated teeth can fail. Int. Endod. J. 2001, 34, 1-10. [CrossRef]

7. Vire, D.E. Failure of endodontically treated teeth: Classification and evaluation. J. Endod. 1991, 17, 338-342. [CrossRef]

8. Ng, Y.L.; Mann, V.; Gulabivala, K. A prospective study of the factors affecting outcomes of non-surgical root canal treatment: Part 2: Tooth survival. Int. Endod. J. 2011, 44, 610-625. [CrossRef]

9. Ricucci, D.; Siqueira, J.F.; Bate, A.L.; Pitt Ford, T.R. Histologic Investigation of Root Canal-treated Teeth with Apical Periodontitis: A Retrospective Study from Twenty-four Patients. J. Endod. 2009, 35, 493-502. [CrossRef] [PubMed]

10. Arnold, M.; Ricucci, D.; Siqueira, J.F. Infection in a complex network of apical ramifications as the cause of persistent apical periodontitis: A case report. J. Endod. 2013, 39, 1179-1184. [CrossRef]

11. Costa, F.F.N.P.; Pacheco-Yanes, J.; Siqueira, J.F.; Oliveira, A.C.S.; Gazzaneo, I.; Amorim, C.A.; Santos, P.H.B.; Alves, F.R.F. Association between missed canals and apical periodontitis. Int. Endod. J. 2019, 52, 400-406. [CrossRef] [PubMed]

12. Danesh, N.; Ljunggren, A.C.; Wolf, E.; Fransson, H. Development of criteria for investigation of periapical tissue from root-filled teeth. Acta Odontol. Scand. 2019, 77, 269-274. [CrossRef] [PubMed]

13. Avila, G.; Galindo-Moreno, P.; Soehren, S.; Misch, C.E.; Morelli, T.; Wang, H.-L. A Novel Decision-Making Process for Tooth Retention or Extraction. J. Periodontol. 2009, 80, 476-491. [CrossRef] [PubMed]

14. Chatzopoulos, G.S.; Koidou, V.P.; Lunos, S.; Wolff, L.F. Implant and root canal treatment: Survival rates and factors associated with treatment outcome. J. Dent. 2018, 71, 61-66. [CrossRef]

15. Segura-Egea, J.J.; Martín-González, J.; Castellanos-Cosano, L. Endodontic medicine: Connections between apical periodontitis and systemic diseases. Int. Endod. J. 2015, 48, 933-951. [CrossRef]

16. Segura-Egea, J.J.; Cabanillas-Balsera, D.; Jiménez-Sánchez, M.C.; Martín-González, J. Endodontics and diabetes: Association versus causation. Int. Endod. J. 2019, 52, 790-802. [CrossRef]

17. Marending, M.; Peters, O.A.; Zehnder, M. Factors affecting the outcome of orthograde root canal therapy in a general dentistry hospital practice. Oral Surg. Oral Med. Oral Pathol. Oral Radiol. Endod. 2005, 99, 119-124. [CrossRef]

18. Cabanillas-Balsera, D.; Martín-González,J.; Montero-Miralles, P.; Sánchez-Domínguez, B.; Jiménez-Sánchez, M.C.; Segura-Egea, J.J. Association between diabetes and nonretention of root filled teeth: A systematic review and meta-analysis. Int. Endod. J. 2019, 52, 297-306. [CrossRef] 
19. Duncan, H.F.; Pitt Ford, T.R. The potential association between smoking and endodontic disease. Int. Endod. J. 2006, 39, 843-854. [CrossRef]

20. Doyle, S.L.; Hodges, J.S.; Pesun, I.J.; Law, A.S.; Bowles, W.R. Retrospective cross sectional comparison of initial nonsurgical endodontic treatment and single-tooth implants. Compend. Contin. Educ. Dent. 2007, 28, 296-301. [CrossRef]

21. Ghattas Ayoub, C.; Aminoshariae, A.; Bakkar, M.; Ghosh, S.; Bonfield, T.; Demko, C.; Montagnese, T.A.; Mickel, A.K. Comparison of IL-1 $\beta$, TNF- $\alpha$, hBD-2, and hBD-3 Expression in the Dental Pulp of Smokers Versus Nonsmokers. J. Endod. 2017, 43, 2009-2013. [CrossRef] [PubMed]

22. Haverstock, B.D.; Mandracchia, V.J. Cigarette smoking and bone healing: Implications in foot and ankle surgery. J. Foot Ankle Surg. 1998, 37, 69-74. [CrossRef]

23. Pinto, K.P.; Ferreira, C.M.; Maia, L.C.; Sassone, L.M.; Fidalgo, T.K.S.; Silva, E.J.N.L. Does tobacco smoking predispose to apical periodontitis and endodontic treatment need? A systematic review and meta-analysis. Int. Endod. J. 2020, 53, 1068-1083. [CrossRef]

24. Krall, E.A.; Sosa, C.A.; Garcia, C.; Nunn, M.E.; Caplan, D.J.; Garcia, R.I. Cigarette Smoking Increases the Risk of Root Canal Treatment. J. Dent. Res. 2006, 85, 313-317. [CrossRef] [PubMed]

25. Walter, C.; Rodriguez, F.R.; Taner, B.; Hecker, H.; Weiger, R. Association of tobacco use and periapical pathosis-A systematic review. Int. Endod. J. 2012, 45, 1065-1073. [CrossRef]

26. López-López, J.; Castellanos-Cosano, L.; Estrugo-Devesa, A.; Gómez-Vaquero, C.; Velasco-Ortega, E.; Segura-Egea, J.J. Radiolucent periapical lesions and bone mineral density in post-menopausal women. Gerodontology 2015, 32, 195-201. [CrossRef]

27. Moher, D.; Liberati, A.; Tetzlaff, J.; Altman, D.G. Preferred reporting items for systematic reviews and meta-analyses: The PRISMA statement. BMJ 2009, 339, 332-336. [CrossRef]

28. Stroup, D.F.; Berlin, J.A.; Morton, S.C.; Olkin, I.; Williamson, G.D.; Rennie, D.; Moher, D.; Becker, B.J.; Sipe, T.A.; Thacker, S.B. Meta-analysis of observational studies in epidemiology: A proposal for reporting. Meta-analysis Of Observational Studies in Epidemiology (MOOSE) group. JAMA 2000, 283, 2008-2012. [CrossRef]

29. Bader, J.D. Systematic reviews and their implications for dental practice. Tex. Dent. J. 2004, 121, 380-387.

30. Higgins, J.P.T.; Thompson, S.G. Quantifying heterogeneity in a meta-analysis. Stat. Med. 2002, 21, 1539-1558. [CrossRef]

31. Sterne, J.A.C.; Egger, M. Funnel plots for detecting bias in meta-analysis: Guidelines on choice of axis. J. Clin. Epidemiol. 2001, 54, 1046-1055. [CrossRef]

32. Lewis, S.; Clarke, M. Forest plots: Trying to see the wood and the trees. BMJ 2001, 322, 1479-1480. [CrossRef] [PubMed]

33. The Cochrane Collaboration. Review Manager (RevMan); Computer program, Version 5.4; The Cochrane Collaboration: London, UK, 2020.

34. Oxford Centre for Evidence-Based Medicine. Levels of Evidence-CEBM; Oxford Centre for Evidence-Based Medicine: Oxford, UK, 2020.

35. Guyatt, G.; Oxman, A.D.; Akl, E.A.; Kunz, R.; Vist, G.; Brozek, J.; Norris, S.; Falck-Ytter, Y.; Glasziou, P.; Debeer, H.; et al. GRADE guidelines: 1 . Introduction-GRADE evidence profiles and summary of findings tables. J. Clin. Epidemiol. 2011, 64, 383-394. [CrossRef] [PubMed]

36. Guyatt, G.H.; Oxman, A.D.; Vist, G.; Kunz, R.; Brozek, J.; Alonso-Coello, P.; Montori, V.; Akl, E.A.; Djulbegovic, B.; Falck-Ytter, Y.; et al. GRADE guidelines: 4. Rating the quality of evidence-Study limitations (risk of bias). J. Clin. Epidemiol. 2011, 64, 407-415. [CrossRef] [PubMed]

37. Sterne, J.A.; Hernán, M.A.; Reeves, B.C.; Savović, J.; Berkman, N.D.; Viswanathan, M.; Henry, D.; Altman, D.G.; Ansari, M.T.; Boutron, I.; et al. ROBINS-I: A tool for assessing risk of bias in non-randomised studies of interventions. BMJ 2016, 355. [CrossRef]

38. Zadik, Y.; Sandler, V.; Bechor, R.; Salehrabi, R. Analysis of factors related to extraction of endodontically treated teeth. Oral Surg. Oral Med. Oral Pathol. Oral Radiol. Endodontol. 2008, 106, 31-35. [CrossRef]

39. Zhong, Y.; Garcia, R.; Kaye, E.K.; Cai, J.; Kaufman, J.S.; Trope, M.; Wilcosky, T.; Caplan, D.J. Association of endodontic involvement with tooth loss in the veterans affairs dental longitudinal study. J. Endod. 2010, 36, 1943-1949. [CrossRef]

40. Touré, B.; Faye, B.; Kane, A.W.; Lo, C.M.; Niang, B.; Boucher, Y. Analysis of Reasons for Extraction of Endodontically Treated Teeth: A Prospective Study. J. Endod. 2011, 37, 1512-1515. [CrossRef] 
41. Olcay, K.; Ataoglu, H.; Belli, S. Evaluation of Related Factors in the Failure of Endodontically Treated Teeth: A Cross-sectional Study. J. Endod. 2018, 44, 38-45. [CrossRef]

42. Khalighinejad, N.; Aminoshariae, A.; Kulild, J.C.; Wang, J.; Mickel, A. The Influence of Periodontal Status on Endodontically Treated Teeth: 9-year Survival Analysis. J. Endod. 2017, 43, 1781-1785. [CrossRef]

43. Doyle, S.L.; Hodges, J.S.; Pesun, I.J.; Baisden, M.K.; Bowles, W.R. Factors affecting outcomes for single-tooth implants and endodontic restorations. J. Endod. 2007, 33, 399-402. [CrossRef]

44. Costa, T.H.R.; de Figueiredo Neto, J.A.; de Oliveira, A.E.F.; de Figueierdo Lopes e Maia, M.; de Almeida, A.L. Association between chronic apical periodontitis and coronary artery disease. J. Endod. 2014, 40, $164-167$. [CrossRef] [PubMed]

45. Jiménez-Sánchez, M.; Cabanillas-Balsera, D.; Areal-Quecuty, V.; Velasco-Ortega, E.; Martín-González, J.; Segura-Egea, J. Cardiovascular diseases and apical periodontitis: Association not always implies causality. Med. Oral Patol. Oral Cir. Bucal 2020, 25, e652-e659. [CrossRef]

46. Nagendrababu, V.; Segura-Egea, J.J.; Fouad, A.F.; Pulikkotil, S.J.; Dummer, P.M.H. Association between diabetes and the outcome of root canal treatment in adults: An umbrella review. Int. Endod. J. 2020, 53, 455-466. [CrossRef] [PubMed]

47. Segura-Egea, J.J.; Martín-González, J.; Cabanillas-Balsera, D.; Fouad, A.F.; Velasco-Ortega, E.; López-López, J. Association between diabetes and the prevalence of radiolucent periapical lesions in root-filled teeth: Systematic review and meta-analysis. Clin. Oral Investig. 2016, 20, 1133-1141. [CrossRef]

48. Mindiola, M.J.; Mickel, A.K.; Sami, C.; Jones, J.J.; Lalumandier, J.A.; Nelson, S.S. Endodontic treatment in an American Indian population: A 10-year retrospective study. J. Endod. 2006, 32, 828-832. [CrossRef]

49. Warnakulasuriya, S.; Dietrich, T.; Bornstein, M.M.; Casals Peidró, E.; Preshaw, P.M.; Walter, C.; Wennström, J.L.; Bergström, J. Oral health risks of tobacco use and effects of cessation. Int. Dent. J. 2010, 60, 7-30. [CrossRef]

50. Mai, X.; Wactawski-Wende, J.; Hovey, K.M.; LaMonte, M.J.; Chen, C.; Tezal, M.; Genco, R.J. Associations between smoking and tooth loss according to the reason for tooth loss: The Buffalo OsteoPerio Study. J. Am. Dent. Assoc. 2013, 144, 252-265. [CrossRef]

51. Leite, F.R.M.; Nascimento, G.G.; Scheutz, F.; López, R. Effect of Smoking on Periodontitis: A Systematic Review and Meta-regression. Am. J. Prev. Med. 2018, 54, 831-841. [CrossRef]

52. Graetz, C.; Plaumann, A.; Schlattmann, P.; Kahl, M.; Springer, C.; Sälzer, S.; Gomer, K.; Dörfer, C.; Schwendicke, F. Long-term tooth retention in chronic periodontitis-Results after 18 years of a conservative periodontal treatment regimen in a university setting. J. Clin. Periodontol. 2017, 44, 169-177. [CrossRef]

53. De Maat, M.P.M.; Kluft, C. The association between inflammation markers, coronary artery disease and smoking. Vascul. Pharmacol. 2002, 39, 137-139. [CrossRef]

54. Johnson, G.K.; Guthmiller, J.M. The impact of cigarette smoking on periodontal disease and treatment. Periodontol. 2000 2007, 44, 178-194. [CrossRef] [PubMed]

55. Trowbridge, H.O. Immunological aspects of chronic inflammation and repair. J. Endod. 1990, 16, 54-61. [CrossRef]

56. Holt, P.G. Immune and inflammatory function in cigarette smokers. Thorax 1987, 42, 241-249. [CrossRef]

57. Tappia, P.S.; Troughton, K.L.; Langley-Evans, S.C.; Grimble, R.F. Cigarette smoking influences cytokine production and antioxidant defences. Clin. Sci. 1995, 88, 485-489. [CrossRef]

58. Bazdyrev, E.D.; Polikutina, O.M.; Kalichenko, N.A.; Slepynina, Y.S.; Uchasova, E.G.; Pavlova, V.Y.; Barbarash, O.L. Relationship between smoking and indicators of systemic inflammation in patients with coronary heart disease. Klin. Med. (Mosk). 2017, 95, 264-271.

59. Fröhlich, M.; Sund, M.; Löwel, H.; Imhof, A.; Hoffmeister, A.; Koenig, W. Independent association of various smoking characteristics with markers of systemic inflammation in men. Results from a representative sample of the general population (MONICA Augsburg Survey 1994/95). Eur. Heart J. 2003, 24, 1365-1372. [CrossRef]

60. Ijzerman, R.G.; Serne, E.H.; Van Weissenbruch, M.H.; De Jongh, R.T.; Stehouwer, C.D.A. Cigarette smoking is associated with an acute impairment of microvascular function in humans. Clin. Sci. 2003, 104, $247-252$. [CrossRef]

61. Wong, L.S.; Green, H.M.; Feugate, J.E.; Yadav, M.; Nothnagel, E.A.; Martins-Green, M. Effects of second-hand smoke on structure and function of fibroblasts, cells that are critical for tissue repair and remodeling. BMC Cell Biol. 2004, 5. [CrossRef] 
62. Eder, A.; Koegl, E.; Von Duvillard, S.P.; Sinzinger, H.; Berent, R. Influence of cigarette smoking on synthesis of eicosanoids, isoprostanes and lipoxygenase metabolites in apical periodontitis. Arch. Oral Biol. 2012, 57, 1133-1140. [CrossRef]

63. Bergstrom, J.; Babcan, J.; Eliasson, S. Tobacco smoking and dental periapical condition. Eur. J. Oral Sci. 2004, 112, 115-120. [CrossRef] [PubMed]

64. Balto, H.A.; Alabdulaaly, L.; Bahammam, S.; Al-Ekrish, A.A. Comparative analysis of prevalence of apical periodontitis in smokers and non-smokers using cone-beam computed tomography. Saudi Dent. J. 2019, 31, 52-57. [CrossRef] [PubMed]

(C) 2020 by the authors. Licensee MDPI, Basel, Switzerland. This article is an open access article distributed under the terms and conditions of the Creative Commons Attribution (CC BY) license (http://creativecommons.org/licenses/by/4.0/). 